\title{
Lung transplantation and coronavirus disease 2019 (COVID-19): a roadmap for the enduring pandemic
}

\author{
Norihisa Shigemura ${ }^{1}$, Francis Cordova ${ }^{2}$, Awori J. Hayanga ${ }^{3}$, Gerard Criner ${ }^{2}$, Yoshiya Toyoda ${ }^{1}$ \\ ${ }^{1}$ Division of Cardiovascular Surgery, Department of Surgery, Temple University Health System, Lewis Katz School of Medicine at Temple \\ University, Philadelphia, PA, USA; ${ }^{2}$ Department of Thoracic Medicine and Surgery, Temple University Health System and Lewis Katz School \\ of Medicine at Temple University, Philadelphia, PA, USA; ${ }^{3}$ Department of Cardiovascular and Thoracic Surgery, West Virginia University, \\ Morgantown, WV, USA \\ Correspondence to: Norihisa Shigemura, MD, PhD. Professor of Surgery, Surgical Director of Lung Transplantation and Lung Failure, Division of Cardiovascular \\ Surgery, Temple University Health System, Lewis Katz School of Medicine, Philadelphia, PA, USA. Email: Norihisa.Shigemura@tuhs.temple.edu.
}

Submitted Oct 19, 2021. Accepted for publication Nov 05, 2021.

doi: $10.21037 /$ jtd-21-1667

View this article at: https://dx.doi.org/10.21037/jtd-21-1667

\section{Introduction}

Due to the ongoing coronavirus disease 2019 (COVID-19) pandemic, organ transplant specialists remain uncertain of directions and goals before and after organ replacement therapy (1). Reports of COVID-19 outcomes in lung transplant recipients have been limited, comprising a small number of case series without a consistent approach between those infected post-transplant and those who became candidates for a transplant post-infection (2-5). Nonetheless, the pandemic has inspired new roles for lung failure specialists who must care for patients who develop acute respiratory distress syndrome (ARDS) and progressive pulmonary fibrosis due to COVID-19 (6). Specialists who can handle organ replacement therapy including extracorporeal membrane oxygenation (ECMO) and lung transplantation are an integral part of the multidisciplinary care team $(2,7)$.

In the midst of the first phase of the pandemic, we offered our insights regarding the direction of lung transplantation during the pandemic as specialists at a highvolume center in a geographical area with high COVID-19 infection rates (8). Herein, we expand our review of outcomes in lung transplant recipients with COVID-19 infections and offer our phased approach as well as insights for lung transplantation for post covid lung failure as the sequelae of COVID-19 infection in light of our large outcomes data for the recipients with positive covid after lung transplantation.

\section{Extended experiences and outcomes in lung transplant recipients with COVID-19 infections at Temple University Hospital}

We analyzed prospectively collected data from lung transplant recipients who developed COVID-19-positive pneumonia and patients considered for lung transplantation for COVID-19 sequelae at Temple University Hospital. Patients were considered COVID-19-positive based on PCR testing or on the consensus opinion of the multidisciplinary team after considering chest computed tomography (CT) findings and clinical presentation. The standard workup included COVID-19 serum biomarkers and chest CT. Severity of illness was defined according to the sequential organ failure assessment (SOFA) score and the recently validated $4 \mathrm{C}$ mortality score (9).

As of April 15, 2021, we identified 52 patients who had received a lung transplant and were diagnosed with COVID-19 pneumonia after transplantation. Twenty-nine $(56 \%)$ underwent lung transplantation prior to 2020; 23 (44\%) received a transplant in 2020. Applying the criteria for hospital admission developed by the Temple University COVID-19 Treatment and Research Group (10), 47 of the 52 patients $(90 \%)$ were admitted to the hospital for an average of 12 days (range, 1-61 days) (Table 1). Following completion of treatment, 37 patients had been discharged from the hospital.

The overall mortality rate in lung transplant recipients with COVID-19 pneumonia was $25 \%(13 / 52)$ and 
Table 1 Patient characteristics

\begin{tabular}{|c|c|}
\hline Characteristic & $\begin{array}{l}\text { Lung transplant } \\
\text { recipients with COVID-19 } \\
\text { pneumonia, } \mathrm{n}^{\star}\end{array}$ \\
\hline All Patients & 52 \\
\hline \multicolumn{2}{|l|}{ Date of transplant } \\
\hline Before January 1, 2020 & $29(56 \%)$ \\
\hline After January 1, 2020 & $23(44 \%)$ \\
\hline Age, median years (range) & $65(44-81)$ \\
\hline \multicolumn{2}{|l|}{ Sex } \\
\hline Male & 37 (71\%) \\
\hline Female & $15(29 \%)$ \\
\hline $\begin{array}{l}\text { Time from transplant to COVID } \\
\text { diagnosis, median (range) }\end{array}$ & $\begin{array}{l}1.3 \text { years } \\
\text { ( } 7 \text { days }-4.2 \text { years })\end{array}$ \\
\hline \multicolumn{2}{|l|}{ Comorbidities } \\
\hline Age $>70$ years & $36(69 \%)$ \\
\hline Renal insufficiency & $35(67 \%)$ \\
\hline Poorly controlled diabetes & $11(21 \%)$ \\
\hline Obesity (BMI >32) & $4(8 \%)$ \\
\hline $\begin{array}{l}4 \mathrm{C} \text { score at the time of admission, } \\
\text { median (range) }\end{array}$ & $10(2-15)$ \\
\hline $\begin{array}{l}\text { SOFA score at the time of admission, } \\
\text { median (range) }\end{array}$ & $3.1(1-12)$ \\
\hline Required ICU admission & $14(27 \%)$ \\
\hline \multicolumn{2}{|l|}{ Chest CT findings with GGO } \\
\hline Category \#1 & $33(63 \%)$ \\
\hline Category \#2 & $7(13 \%)$ \\
\hline Category \#3 & $12(23 \%)$ \\
\hline \multicolumn{2}{|l|}{ COVID-19 disease biomarkers } \\
\hline $\begin{array}{l}\text { Ferritin (peak), median in } \mathrm{ng} / \mathrm{mL} \\
\text { (range) }\end{array}$ & $1,961(85-18,000)$ \\
\hline $\begin{array}{l}\text { D-dimer (peak), median in } \mu \mathrm{g} / \mathrm{mL} \\
\text { (range) }\end{array}$ & $8,562(425-59,000)$ \\
\hline $\begin{array}{l}\text { C-reactive protein (peak), median in } \\
\mathrm{mg} / \mathrm{dL} \text { (range) }\end{array}$ & $11.6(0.3-39.7)$ \\
\hline \multicolumn{2}{|l|}{ Treatment } \\
\hline Pulse steroids & $30(58 \%)$ \\
\hline Remdesivir & $21(40 \%)$ \\
\hline Anakinra & $5(10 \%)$ \\
\hline Intravenous immunoglobulin & $12(23 \%)$ \\
\hline
\end{tabular}

Table 1 (continued)

\begin{tabular}{ll}
\hline Characteristic & $\begin{array}{l}\text { Lung transplant } \\
\text { recipients with COVID-19 } \\
\text { pneumonia, }{ }^{*}\end{array}$ \\
\hline Tocilizumab & $8(15 \%)$ \\
Convalescent plasma & $5(10 \%)$ \\
Outcomes & \\
Length of hospital stay, median & $12(1-61)$ \\
days (range) & $14(27 \%)$ \\
Intubation & $5(10 \%)$ \\
ECMO & $4(8 \%)$ \\
Renal replacement therapy & $37(71 \%)$ \\
Discharged from hospital & $2(4 \%)$ \\
Remained hospitalized & $13(25 \%)$ \\
Death & $8 / 29(28 \%)$ \\
Transplant before January 1, 2020 & $5 / 23(22 \%)$ \\
Transplant after January 1, 2020 & $8 / 511^{\dagger}(1.6 \%)$ \\
Mortality by date of transplant (based on total lung transplants \\
performed)
\end{tabular}

*, unless otherwise specified; ${ }^{\dagger}$, underwent lung transplant 2016-2019. BMI, body mass index; 4C score, coronavirus clinical characterization consortium score; SOFA, sequential organ failure assessment; ICU, intensive care unit; GGO, ground glass opacity; ECMO, extracorporeal membrane oxygenation.

included 5 deaths out of 131 lung transplants in 2020 (3.8\%), and 8 deaths of 511 lung transplants from 2016 through 2019 (1.6\%). Of the 5 patients who underwent transplantation after January 1, 2020 and died, 3 were infected with COVID-19 as inpatients in the ICU following the transplant procedure and died of progressive septic shock despite all available treatments including ECMO. Multivariate analysis identified recipient age older than 70 years, stage 3 or greater chronic kidney disease, and higher SOFA and $4 \mathrm{C}$ scores at the time of admission as significant risk factors for mortality $(\mathrm{P}<0.05)$.

\section{Lung transplantation in patients with post- covid lung failure}

Our program has received an increasing number of requests

Table 1 (continued) 
for consultations regarding patients at outside institutions who had COVID-19 pneumonia and developed ARDS requiring further management. Almost all were already supported by mechanical ventilation in the ICU; some were critically ill and supported with prolonged ECMO. Currently, the indications we use for lung transplantation for post-COVID lung failure are, (I) at least 3 weeks from the initial onset of COVID-associated symptoms and 2 COVID-negative nasal swab tests post-infection; (II) single organ failure (lung failure only); (III) age younger than 70 years; (IV) acceptable physical viability if the patient is on ECMO; and (V) the standard criteria of the Temple University Lung Transplant Program. Physical viability is the most challenging criteria to assess. Indeed, after duly evaluating patients using all available telemedicine tools, we had to decline most for transplant due to their severely deconditioned status.

Since September 2020, 15 patients with lung damage caused by COVID infection have been approved by the lung transplant selection committee and listed for transplant. Three of the patients were supported by ECMO at the time of listing, progressed to septic shock, and died while waiting for lungs. Three are currently on the waiting list, and nine underwent lung transplantation while all the patients were already discharged from the hospital and stayed at home as of August 15, 2021.

\section{Discussion}

As a high-volume transplant center handling a unique cohort of patients and given our extensive experience with artificial respiratory support, we appreciate our new role in caring for patients with post-COVID lung failure. However, as the pandemic continues without promise of a definite end, we think it is critically important to navigate such challenging practice correctly and eventually save more patients even with limited donor organs and availability of health care professionals during the pandemic. To that end, lung transplantation in patients with post-COVID lung failure should be carefully developed, and the current mortality of patients infected after lung transplantation requires our simultaneous attention. There have been a few reports of patients who were critically ill and profoundly deconditioned on prolonged ECMO post-COVID-19 who underwent lung transplantation with successful outcomes $(3,4)$. Those excellent outcomes could have been achieved by a very experienced transplant team but we need to be mindful that they are the exceptions at this phase of the COVID-119 disease treatment that should not be extended in an unfounded fashion and performed by the teams without experiences.

\section{An evolving but phased approach to lung transplantation for post-COVID lung failure}

When moving to perform lung transplantation for postCOVID lung failure, we advise phase-to-phase steps while simultaneously monitoring admission and mortality rates of COVID-positive lung transplant recipients (Figure 1). The indications for and optimal timing of potential therapeutic options, and evolving approaches with ECMO and transplantation need to be in line with the improving outcomes of medical treatments for COVID-19. We monitor the mortality rate of the COVID-19-positive lung transplant recipients as the primary metric for our phased approach to the new practice of transplantation for postCOVID lung failure due to our firm belief that all treatment options, from upfront medical treatment through ECMO and lung transplantation, should be consistent with progress that improves outcomes during the entirety of treatment for COVID-19 disease. This is our central message in this editorial regarding a consistent approach between those infected post-transplant and those who became candidates for a transplant as the sequelae of COVID-19 infection whereas many questions remain unanswered, particularly regarding effective and timely testing and treatments including a COVID-19-specific vaccination, anti-viral therapies, and inhibition of potentially deadly cytokine storm inflammatory cascades in the patients with heavily suppressed immune system.

Encouragingly, the most recent 3-month mortality rate among the COVID-positive transplant recipients at our institution improved from $52 \%$ (between $03 / 2020$ and $06 / 2020)$ to $15 \%(03 / 2020$ and $06 / 2021)$. Based on this improvement, we have been able to continue to evaluate referred patients with post-COVID lung failure for consideration for lung transplantation and list them when appropriate.

During this long-lasting pandemic full of uncertainty and excessive expectations, it is crucial that the lung-failure and lung-transplant specialists, who play pivotal roles on the front lines, lead the entire team as they tackle the challenges associated with COVID-19 using a data-driven approach. This is how we will win the battle against COVID-19. 


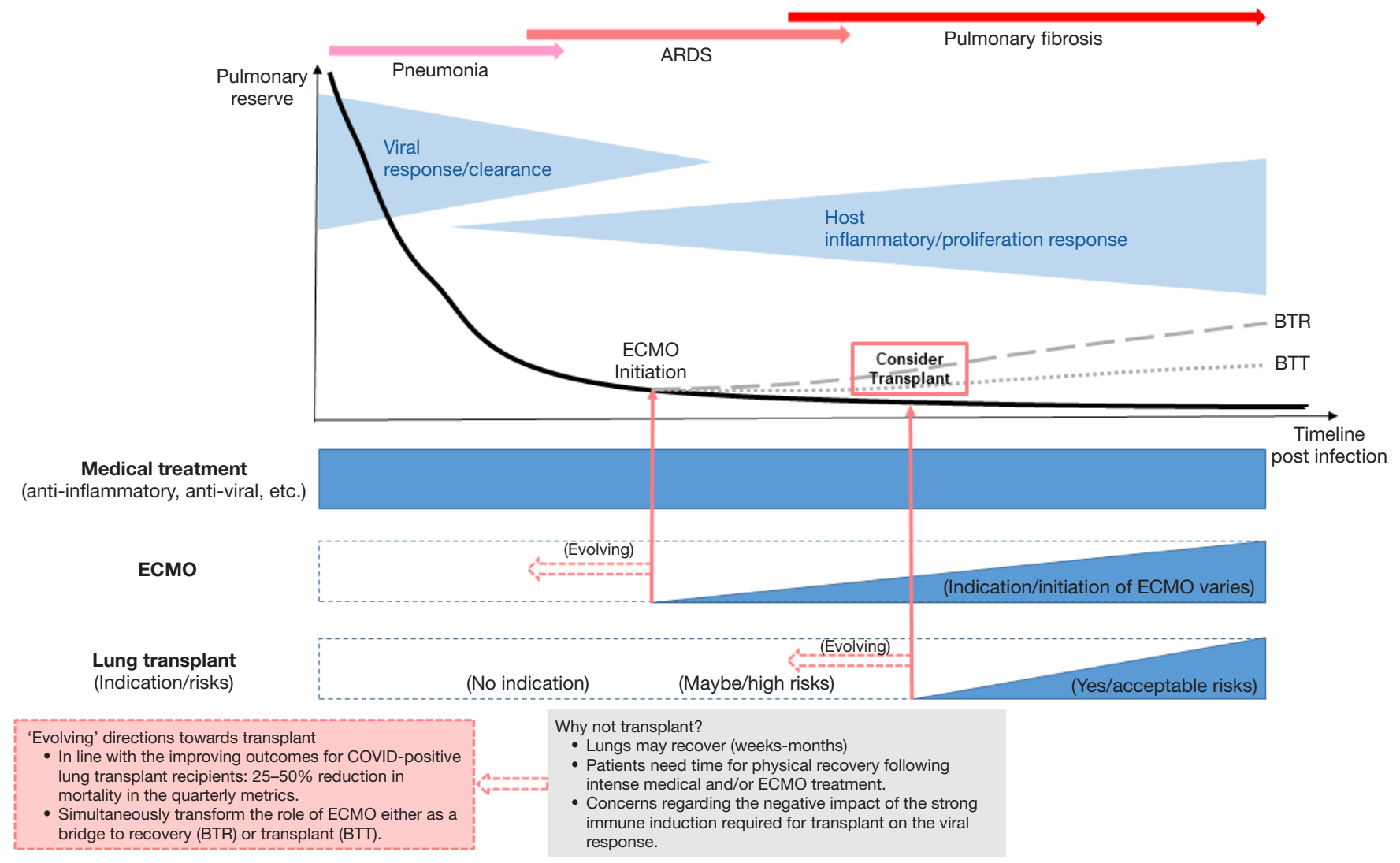

Figure 1 Consideration of lung transplantation for the sequelae of COVID infection. ECMO, extracorporeal membrane oxygenation; ARDS, acute respiratory distress syndrome; BTR, bridge to recovery; BTT, bridge to transplant; COVID, coronavirus disease.

\section{Acknowledgments}

Funding: None.

\section{Footnote}

Provenance and Peer Review: This article was commissioned by the editorial office, Fournal of Thoracic Disease. The article did not undergo external peer review.

Conflicts of Interest: The authors have completed the ICMJE uniform disclosure form (available at https://dx.doi. org/10.21037/jtd-21-1667). NS serves as an unpaid editorial board member of Journal of Thoracic Disease. The other authors have no conflicts of interest to declare.

Ethical Statement: The authors are accountable for all aspects of the work in ensuring that questions related to the accuracy or integrity of any part of the work are appropriately investigated and resolved.

Open Access Statement: This is an Open Access article distributed in accordance with the Creative Commons Attribution-NonCommercial-NoDerivs 4.0 International License (CC BY-NC-ND 4.0), which permits the noncommercial replication and distribution of the article with the strict proviso that no changes or edits are made and the original work is properly cited (including links to both the formal publication through the relevant DOI and the license). See: https://creativecommons.org/licenses/by-nc-nd/4.0/.

\section{References}

1. Ravanan R, Callaghan CJ, Mumford L, et al. SARS-CoV-2 infection and early mortality of waitlisted and solid organ transplant recipients in England: A national cohort study. Am J Transplant 2020;20:3008-18. 
2. Chen JY, Qiao K, Liu F, et al. Lung transplantation as therapeutic option in acute respiratory distress syndrome for coronavirus disease 2019-related pulmonary fibrosis. Chin Med J (Engl) 2020;133:1390-6.

3. Lang C, Jaksch P, Hoda MA, et al. Lung transplantation for COVID-19-associated acute respiratory distress syndrome in a PCR-positive patient. Lancet Respir Med 2020;8:1057-60.

4. Bharat A, Querrey M, Markov NS, et al. Lung transplantation for patients with severe COVID-19. Sci Transl Med 2020;12:eabe4282.

5. Messika J, Eloy P, Roux A, et al. COVID-19 in Lung Transplant Recipients. Transplantation 2021;105:177-86.

6. Wang D, Hu B, Hu C, et al. Clinical Characteristics of 138 Hospitalized Patients With 2019 Novel CoronavirusInfected Pneumonia in Wuhan, China. JAMA 2020;323:1061-9.

7. Falcoz PE, Monnier A, Puyraveau M, et al. Extracorporeal
Membrane Oxygenation for Critically Ill Patients with COVID-19-related Acute Respiratory Distress Syndrome: Worth the Effort? Am J Respir Crit Care Med 2020;202:460-3.

8. Shigemura N, Cordova F, Criner G, et al. Current precautions and future directions in lung transplantation during the COVID-19 pandemic - a single center cohort study. Transpl Int 2020;33:1453-7.

9. Knight SR, Ho A, Pius R, et al. Risk stratification of patients admitted to hospital with covid-19 using the ISARIC WHO Clinical Characterisation Protocol: development and validation of the 4C Mortality Score. BMJ 2020;370:m3339.

10. Chowdhury JM, Patel M, Zheng M, et al. Mobilization and Preparation of a Large Urban Academic Center during the COVID-19 Pandemic. Ann Am Thorac Soc 2020;17:922-5.

Cite this article as: Shigemura N, Cordova F, Hayanga AJ, Criner G, Toyoda Y. Lung transplantation and coronavirus disease 2019 (COVID-19): a roadmap for the enduring pandemic. J Thorac Dis 2021;13(12):6755-6759. doi: 10.21037/jtd21-1667 